\title{
LA U.D.C.A FRENTE AL SECTOR PÚBLICO Y PRIVADO
}

Luis Carlos Concha Bustos ${ }^{1}$

La relación que tiene la Universidad de Ciencias Aplicadas y Ambientales U.D.C.A con su entorno académico, social, político y económico es un propósito misional, sobre el cual se mantiene, permanente, actividad y dinamismo. En el diseño y puesta en marcha de sus programas de formación, de investigación y de proyección social, se incorporan siempre principios de impulso y de compromiso social, de equidad, de pertinencia y de responsabilidad con el entorno; conducentes a fortalecer e incrementar las relaciones de cooperación e intercambio con los sectores público y privado, en el marco de respeto mutuo a la autonomía, el beneficio recíproco y la repercusión e impacto sociales. La U.D.C.A es consciente de la responsabilidad social que le asiste y de la importancia que, en consecuencia, tiene el tipo de relaciones interinstitucionales y sociales que establezca a nivel local, regional, nacional e internacional, en los campos de la academia, de las agencias e instituciones gubernamentales y no gubernamentales, del sector productivo, colectivos y agremiaciones sociales, culturales, científicas y tecnológicas; que son vistos como escenarios de trabajo en los cuales sus estudiantes y egresados, encuentran el acercamiento y las vivencias en las realidades y oportunidades laborales; en cumplimiento de una función eminentemente social.

\section{PROGRAMAS, LÍNEAS DE ACCIÓN Y LOGROS}

Las diversas acciones y proyectos ejecutados desde el año 1983, año en que se creó la Institución, hasta la fecha, han permitido consolidar programas y líneas de acción que son ejecutadas desde las distintas unidades operativas de la U.D.C.A. En este recuento de las relaciones con el sector público y privado, se pretende no relacionar los hechos cumplidos en los veinticinco años

\footnotetext{
1 Médico Veterinario y Zootecnista, M.Sc. en Educación. Asesor de Rectoría U.D.C.A e-mail: lconcha@udca. edu.co
}

de vida de la institución, sino presentar una síntesis de lo que, en nuestro criterio, es oportuno consignar como referentes y frutos de nuestro trabajo; a sabiendas de que es posible, se omitan involuntariamente algunos hechos de vital importancia en el desarrollo, gestión y vida de la Universidad. En este orden de ideas, se resalta:

\section{En el programa de las relaciones universidad sector productivo}

Concebido como un programa clave en la vida de la Universidad, está direccionado a velar y mantener un permanente acercamiento, vínculos y ejecuciones de carácter científico y tecnológico con el sector productivo, que concluyan en avances significativos, en términos de desarrollo, de eficiencia y de eficacia. Ejemplos de de estas acciones son los trabajos realizados con la Base Militar de Tolemaida, la Brigada Trece del Ejercito, el Fondo Rotatorio del Ejercito, los Fondos Ganaderos de Cundinamarca, Valle y Huila; CENIACUA, CENIPALMA, FEDEPAPA; la Fundación Corona, CTELCA, GCR, Laboratorios LIMOR, Laboratorios California y Laboratorios VECOL, entre otros. Estas experiencias dieron lugar a que la Universidad creara la UNIDAD Gerencial de Desarrollo de Tecnologías Agropecuarias. Su portafolio de servicios se ilustra en la tabla 1.

Resultados importantes de esta gestión son: los alcanzados, con el concurso de COLCIENCIAS y CETELCA, en el campo de la producción de embriones in Vitro, con fines comerciales; el proyecto de creación de un laboratorio veterinario de referencia nivel cuatro, en asocio con Laboratorios LIMOR y, contar con modelos para establecer unidades docente productivas realizado con el Fondo Ganadero del Huila.

\section{En el programa de servicio social universitario}

Programa pionero, de lo que más tarde fuera instituido como un propósito nacional. Desde el año 1997 busca 
Tabla 1. Portafolio de servicios de la Unidad Gerencial.

\begin{tabular}{|c|c|}
\hline SERVICIO & CARACTERÍSTICA \\
\hline Plantas Aromáticas y Medicinales & $\begin{array}{l}\text { Asesora el establecimiento de unidades Productivas Sostenibles de Plantas Aromáticas, con destino a } \\
\text { mercados competitivos dentro y fuera del país. }\end{array}$ \\
\hline Agricultura Sostenible & $\begin{array}{l}\text { Asesora en el Manejo de compostaje, labranza de conservación, tecnología de bajos insumos, reciclaje } \\
\text { de nutrientes y explotaciones productivas integrales. }\end{array}$ \\
\hline Cultivos de Tomate Bajo Cubierta & $\begin{array}{l}\text { Presta asesoría y asistencia técnica en análisis marginal de inversiones, obtención de crédito, proyectos } \\
\text { Finagro, instalación de invernaderos, automatización, tecnología del cultivo, mercadeo, comercialización } \\
\text { y post cosecha. }\end{array}$ \\
\hline Clínica de Plantas & $\begin{array}{l}\text { Dedicada al Diagnóstico de problemas fitosanitarios, recomendaciones sobre manejo y alternativas de } \\
\text { control cultural, interpretación de análisis de suelo y foliares. }\end{array}$ \\
\hline Frutales & $\begin{array}{l}\text { Da asesoría y asistencia técnica para el manejo ecofisiológico de frutales tropicales y subtropicales, análisis } \\
\text { financiero y proyección de inversiones, cultivos asociados e intercalados, post cosecha y manejo de la } \\
\text { producción, agroindustria y beneficio. }\end{array}$ \\
\hline $\begin{array}{l}\text { Patología en Pequeños y Grandes } \\
\text { Animales }\end{array}$ & Diagnóstico histopatológico, diagnóstico citológico, servicio de necropsia y disposición de cadáveres. \\
\hline Inmunohistoquímica & $\begin{array}{l}\text { Identificación, sobre muestras tisulares o citológicas, de determinantes antigénicos característicos de } \\
\text { distintas líneas de diferenciación y funcionalismo celular. }\end{array}$ \\
\hline Parasitología & $\begin{array}{l}\text { Coprología para identificación de parásitos gastrointestinales, pulmonares y hepáticos, diagnóstico de } \\
\text { hemoparásitos, diagnóstico parasitológico directo de ectoparásitos. }\end{array}$ \\
\hline Laboratorio Clínico & Cuadro Hemático, parcial de orina, química sanguínea. \\
\hline Microbiología & $\begin{array}{l}\text { Diagnóstico de mastitis en campo, cultivo bacteriológico y antibiograma, examen bacteriológico en } \\
\text { órganos. }\end{array}$ \\
\hline Análisis de agua & Químico y microbiológico. Recuento de coliformes totales y mesófilos. \\
\hline $\begin{array}{l}\text { Control y calidad de leches y sus } \\
\text { derivados }\end{array}$ & Recuento de coliformes y mesófilos -grasa, reductasa, alcoholes, densidad. Pruebas de CMT y HOTIS. \\
\hline Exámenes serológicos & Para Brucilla, Leptospira Neospora - DVD - IBR - Virus sincitial respiratorio bovino \\
\hline Exámenes en Equinos & $\begin{array}{l}\text { Prueba de Elisa para la Influenza y Prueba de Coginns para A.I.E. Exámenes en Porcinos: Prueba de Elisa } \\
\text { para PRRS - Coronavirus, rotavirus - parvovirus - pleuroneumonía, mycoplasma y seudorabia. }\end{array}$ \\
\hline
\end{tabular}


Continuación Tabla 1

\begin{tabular}{|c|c|}
\hline \multirow{4}{*}{$\begin{array}{l}\text { Clínica Veterinaria de Pequeños y } \\
\text { Grandes Animales }\end{array}$} & $\begin{array}{l}\text { Área clínica: Consulta general, preventiva y especializada, para grandes y pequeñas especies; inter- } \\
\text { consulta y hospitalización para grandes y pequeñas especies, Medicina general y especializada, Medicina } \\
\text { preventiva, Control natal en felinos y caninos, observación clínica. }\end{array}$ \\
\hline & $\begin{array}{l}\text { Área terapéutica: Tratamiento ambulatorio e intra-hospitalario tanto médico como quirúrgico, Tratamiento } \\
\text { post quirúrgico, Cuidados intensivos, Atención de partos, Cuidados médicos. }\end{array}$ \\
\hline & $\begin{array}{l}\text { Área diagnóstica: Rayos equis, Ecografía, Endoscopia, Laboratorio clínico, Laboratorio de reproducción, } \\
\text { Diagnóstico quirúrgico, Laboratorio de microbiología, Laboratorio de histolopatología. }\end{array}$ \\
\hline & $\begin{array}{l}\text { Área quirúrgica: Cirugía general, Cirugía ortopédica, Neurocirugía, Cirugía estética, Cirugía obstétrica. } \\
\text { Otros servicios: Hospedaje, Herrajes y corrección de aplomos, Adiestramiento, Alquiler de quirófanos, } \\
\text { Asistencia técnica a criaderos y hatos, Esterilización de materiales, Inseminación artificial, Certificación de } \\
\text { salud, Certificación para viaje, Brigadas de salud, Campañas educativas, Participación y apoyo en eventos } \\
\text { agropecuarios, Seminarios y talleres, Diplomados especializados. }\end{array}$ \\
\hline Diagnóstico Gerencial & $\begin{array}{l}\text { Determinación de los indicadores de gestión para definir el impacto y la calidad de las decisiones de } \\
\text { producción. }\end{array}$ \\
\hline Plan Anual Alimentación Bovina & Balance entre la oferta la demanda de energía disponible para la producción animal. \\
\hline Manejo Reproductivo del Hato & Administración de la salud reproductiva del hato. \\
\hline Manejo de Registros & $\begin{array}{l}\text { Definición de estrategias de recolección de información para la evaluación del desempeño técnico y } \\
\text { económico del sistema }\end{array}$ \\
\hline Forrajes & Estrategias de conservación de forrajes y de suplementación estratégica. \\
\hline $\begin{array}{l}\text { Prevención en desbalances de la } \\
\text { salud }\end{array}$ & $\begin{array}{l}\text { Metodologías y herramientas diagnósticas y definición de estrategias para prevenir desbalances en el } \\
\text { estado de salud de la población con miras a soportar la eficiencia de producción. }\end{array}$ \\
\hline Laboratorio de Nutrición & $\begin{array}{l}\text { Evaluación de la composición y calidad nutricional, de materias primas, concentrados y pastos y } \\
\text { forrajes }\end{array}$ \\
\hline Genética de Peces & $\begin{array}{l}\text { Asistencia técnica aplicada a la acuicultura, a través de programas de selección, caracterización y uso de } \\
\text { cruzamiento entre líneas para la mejora genética de los peces. }\end{array}$ \\
\hline $\begin{array}{l}\text { Alimentación con Subproductos } \\
\text { en Monogástricos }\end{array}$ & $\begin{array}{l}\text { Brinda las herramientas necesarias a los productores, con el fin de poder identificar diferentes procesos } \\
\text { de formulación de dietas, a partir de subproductos agrícolas. }\end{array}$ \\
\hline Asesoría Empresarial & $\begin{array}{l}\text { Especialmente en la Estructura comercial de Empresas Agropecuarias, se tiene el modelo de asesoría y la } \\
\text { experiencia que ha permitido innovar y transformar procesos de Gestión Comercial a empresas del sector, } \\
\text { partiendo de un análisis de situación, un diagnóstico, la formulación y desarrollo de un Plan Gerencial de } \\
\text { desarrollo Comercial, Análisis de Resultados y Proyecciones a corto y largo plazo. }\end{array}$ \\
\hline $\begin{array}{l}\text { Sistemas de Distribución } \\
\text { Eficientes, Logística y Manejo de } \\
\text { Productos Post Cosecha }\end{array}$ & $\begin{array}{l}\text { Asesoría y recomendaciones sobre selección de canales, diseño de empaques, envases y embalajes, } \\
\text { manejo de los sistemas de información gerencial en cuanto a proveedores, clientes y competencia, } \\
\text { almacenamiento y bodegaje. }\end{array}$ \\
\hline $\begin{array}{l}\text { Proyección de las Empresas del } \\
\text { Sector Agropecuario hacia los } \\
\text { Mercados Internacionales }\end{array}$ & $\begin{array}{l}\text { Asesoría y capacitación en procesos de importación y exportación, distribución física internacional, } \\
\text { legalización de insumos, materias primas y productos intermedios (maquinaria, herramienta de trabajo), } \\
\text { negociaciones internacionales y contratación internacional, apertura de nuevos mercados, entre otras. }\end{array}$ \\
\hline Servicio al Cliente y Ventas & $\begin{array}{l}\text { Asesoría, caracterización y capacitación en todo lo pertinente a la psicología y técnicas de ventas, } \\
\text { promoción y merchandising, administración y gerencia de ventas. De igual manera, desarrollar estrategias } \\
\text { mercadológicas de servicio y atención al cliente. }\end{array}$ \\
\hline
\end{tabular}


contribuir al fortalecimiento y desarrollo social, regional y local, apoyando la gestión de los municipios menos desarrollados, en la formulación de políticas sociales, de ordenamiento territorial, en el seguimiento a las problemáticas urbanas y en procesos de organización comunitaria. Contando como acciones prioritarias, la Transferencia de Tecnología, el Mejoramiento de Sistemas de Producción, la Asesoría económica en el manejo de los recursos de la unidad familiar, el Manejo sanitario de especies utilizadas en diversas explotaciones, el Mercadeo y comercialización de productos y la prestación de servicios asistenciales en salud humana. En estas actividades, se ha hecho presencia efectiva, a través de voluntarios en el programa, en 548 municipios distribuidos a lo largo y ancho del territorio colombiano, contando con experiencias bastante significativas en los Municipios de Toca, Soacha-Cazuca, Tauramena, Beltrán, Tame, Arauca, San Francisco, Chia, Tabio, Cota y Suba.

\section{En el programa de gestión social}

Este programa desarrolla labores de carácter social, bajo el enfoque de acción participativa, que buscan contribuir con la solución continua y sistemática de problemas o necesidades sociales y comunitarias, en pro de lograr su autotransformación y desarrollo. En este campo, se han ejecutado sendos proyectos sociales desde el año 1992, contando con ejecuciones tales como:

- Programa de mujer rural: Municipios de Guachetá, Lenguasaque, Tausa, Sutatausa, Tabio (19922001).

- Programa madres cabeza de familia: Ciudad Bolívar, Bogotá (1995-2001).

- Programa SOLNOK: Capacitación a pequeños productores rurales del municipio de Barbosa (19952000).

- Capacitación madres cabeza de familia: Localidad de Suba, Bogotá (2001-2002).

- Formación y capacitación que contribuyen al mejoramiento de la calidad de vida de las mujeres adolescentes, gestantes, lactantes y/o cabeza de familia de extrema pobreza: Localidad Rafael Uribe Uribe (2002-2004).

- Seminarios - talleres: formación técnica laboral a personas cabezas de familia con sentido empresarial solidario: Localidad de Santa Fé (2002-2003).
- Mejoramiento de la calidad y aumento de la cobertura de servicios a grupos vulnerables (Capacitación a madres cabeza de familia). Localidad de Suba, (Elaboración de productos cárnicos y lácteos) (20022004).

- Bogotá ciudad fraterna a través de la capacitación a madres cabeza de familia: Localidad de Suba, (Elaboración de productos de repostería) (2002-2004).

- Capacitación de líderes recreodeportivos: Localidades de Usaquén, Santa Fé y Suba (1999-2004).

- Escuelas de formación deportiva: Localidades de Usaquén y Suba (1999-2004).

Bajo el Programa de Gestión Social, se logró desarrollar otros trabajos, enfocados a optimizar el nivel de vida de los habitantes de otras localidades (Tabla 2).

Bajo este esquema, la Universidad hace presencia efectiva y da cumplimiento a su función social, con el apoyo de sus docentes, directivos y personal especializado, brindando conocimiento, aprendizaje, herramientas y metodologías para poblaciones vulnerables.

\section{En el programa de gestión tecnológica}

Son actividades que buscan proyectar los avances científicos y tecnológicos de la U.D.C.A, a través de la generación, la adecuación, la actualización, la difusión, la comercialización y la protección de la transferencia de tecnología, resultado de los procesos académicos de investigación, de docencia o de asistencia, realizados por la Universidad.

El Subprograma de Emprendimiento Empresarial: fomenta la búsqueda de talento humano dentro de la comunidad universitaria, con habilidades y actitudes de emprendedores empresariales, con el fin de darles la capacitación y las herramientas necesarias que les permitan crear su propia empresa. La ejecución de este subprograma, se ha realizado a través de la vinculación de la Universidad al Fondo Emprender, como medio de apoyo a los estudiantes y los egresados interesados en crear su empresa. Su objetivo, a corto y mediano plazo, es estimular, al interior de la universidad, cada vez más el espíritu emprendedor, mediante actividades de difusión, de promoción y de capacitación a los jóvenes emprendedores. 
Tabla 2. Convenios con Localidades, su función y desarrollo.

\begin{tabular}{|c|c|c|}
\hline CONVENIO & OBJETIVO & CURSOS DESARROLLADOS \\
\hline $\begin{array}{l}\text { 11-022-00-04 } \\
\text { PROYECTO 11-0215-04 }\end{array}$ & $\begin{array}{l}\text { Desarrollar habilidades y destrezas en hombres y } \\
\text { mujeres, jóvenes y adultos de la Localidad de Suba, en el } \\
\text { mantenimiento y embellecimiento paisajístico de parques } \\
\text { y zonas verdes de la localidad y el aprovechamiento de } \\
\text { material reciclado para la elaboración de subproductos. }\end{array}$ & $\begin{array}{l}4 \text { cursos en Jardinería y arreglo de zonas verdes, } 140 \\
\text { beneficiarios; } 2 \text { cursos en Elaboración subproductos } \\
\text { derivados del material reciclado, } 60 \text { beneficiarios. }\end{array}$ \\
\hline $\begin{array}{l}\text { 11-023-00-04 } \\
\text { PROYECTO 11-0172-04 }\end{array}$ & $\begin{array}{l}\text { Mejorar las condiciones de vida de la población de Suba } \\
\text { mediante procesos de capacitación a } 620 \text { personas } \\
\text { de las diferentes UPZ en la cualificación en formación } \\
\text { para el trabajo y apoyo a iniciativas productivas con un } \\
\text { componente de desarrollo de competencias laborales } \\
\text { específicas que les permitan desarrollar su capacidad } \\
\text { empresarial y/o de inserción en el mundo laboral. }\end{array}$ & $\begin{array}{l}2 \text { cursos Cuidado a pacientes en estado terminal y tercera } \\
\text { edad, } 70 \text { beneficiarios; } 3 \text { cursos Ventas y telemercadeo, } \\
90 \text { beneficiarios; } 2 \text { cursos Cuidado y atención del niño, } \\
70 \text { beneficiarios; } 3 \text { cursos Asistente empresarial, } 90 \\
\text { beneficiarios; } 2 \text { cursos Técnicas de servicio al cliente en } \\
\text { bar y restaurante, } 60 \text { beneficiarios; } 3 \text { cursos Organización } \\
\text { de eventos recreativos y deportivos, } 90 \text { beneficiarios; } 2 \\
\text { cursos Elaboración de productos de limpieza y velas, } \\
50 \text { beneficiarios; } 2 \text { cursos Elaboración de productos } \\
\text { procesados, } 50 \text { beneficiarios; } 2 \text { cursos Peluquería canina } \\
\text { y cuidado de mascotas, } 50 \text { beneficiarios. }\end{array}$ \\
\hline $\begin{array}{l}\text { 11-025-00-04 } \\
\text { PROYECTO 11-0174-04 }\end{array}$ & $\begin{array}{l}\text { Mejorar las condiciones de vida de la población de Suba, } \\
\text { a través de la formación para el trabajo y el apoyo a } \\
\text { iniciativas productivas que les permitan desarrollar su } \\
\text { capacidad empresarial y/o de inserción en el mundo } \\
\text { laboral. }\end{array}$ & $\begin{array}{l}2 \text { cursos de Auxiliar en droguería y farmacia, } 60 \\
\text { beneficiarios; } 2 \text { cursos en Corte de carne, comercio } \\
\text { mayorista y detal, } 50 \text { beneficiarios; } 3 \text { cursos de } \\
\text { Mercaderistas e impulsadoras de ventas, } 90 \\
\text { beneficiarios. }\end{array}$ \\
\hline $\begin{array}{l}\text { 11-026-00-04 } \\
\text { PROYECTO 11-0200-04 }\end{array}$ & $\begin{array}{l}\text { Desarrollar actividades de capacitación para madres } \\
\text { cabeza de familia interesadas en crear su propia industria } \\
\text { familiar, ubicadas en la Localidad de Suba. }\end{array}$ & $\begin{array}{l}4 \text { cursos en Elaboración de productos carnicol, } 120 \\
\text { beneficiarios; } 3 \text { cursos en Elaboración de productos } \\
\text { lácteos, } 90 \text { beneficiarios; } 3 \text { cursos en elaboración de } \\
\text { productos de repostería, } 90 \text { beneficiarios. }\end{array}$ \\
\hline $\begin{array}{l}\text { 11-027-00-04 } \\
\text { PROYECTO 11-0214-04 }\end{array}$ & $\begin{array}{l}\text { Realizar un proceso de sensibilización, conscientización, } \\
\text { formación, gestión productiva, generación e } \\
\text { implementación de estrategias asociativas empresariales } \\
\text { frente al manejo de los residuos en algunos sectores } \\
\text { residenciales, dirigidos a la población recicladora. }\end{array}$ & 5 talleres para recicladores, 130 beneficiarios. \\
\hline $\begin{array}{l}\text { 11-012-00-04 UEL- } \\
\text { IDRD-UDCA }\end{array}$ & $\begin{array}{l}\text { Continuar el proceso de formación y especialización en } \\
10 \text { escuelas. Creación de nuevas escuelas. Participación } \\
\text { en torneos de liga de fútbol, organización de diplomados } \\
\text { y seminarios para monitores, instructores y directivos de } \\
\text { escuelas, organización de festivales recreo-deportivos y } \\
\text { sesiones de aeróbicos. }\end{array}$ & $\begin{array}{l}2 \text { diplomados para monitores, instructores y directivos; } \\
3 \text { seminarios para monitores, instructores y directivos; } 6 \\
\text { sesiones de aeróbicos para } 1500 \text { personas. }\end{array}$ \\
\hline
\end{tabular}


Continuación Tabla 2

\begin{tabular}{|c|c|c|}
\hline $\begin{array}{l}\text { Fondo para la } \\
\text { Acción Ambiental } \\
\text { - Municipio de Beltrán, } \\
\text { Cundinamarca } \\
\text { - Proyecto Acción } \\
\text { Colectiva Ambiental } \\
\text { para el Fortalecimiento } \\
\text { de los Agroecosistemas } \\
\text { y la Organización } \\
\text { Comunitaria del } \\
\text { Municipio de Beltrán, } \\
\text { Cundinamarca, } \\
\text { Colombia }\end{array}$ & $\begin{array}{l}\text { Mejorar el manejo comunitario y autogestionario de } \\
\text { los recursos naturales (agua, suelo y bosque). Lograr } \\
\text { que la comunidad adquiera capacidad para establecer } \\
\text { sistemas de producción sostenibles. Incorporar saber } \\
\text { ambiental en el PEI y Construcción del PRAE. Continuar } \\
\text { el proceso de formación y especialización en } 10 \text { escuelas. } \\
\text { Creación de nuevas escuelas. Participación en torneos } \\
\text { de liga de fútbol organización de diplomados y seminarios } \\
\text { para monitores instructores y directivos de escuelas } \\
\text { organización de festivales recreo-deportivos y sesiones } \\
\text { de aeróbicos. }\end{array}$ & $\begin{array}{l}\text { La metodología planteada, los logros alcanzados y el } \\
\text { impacto generado en la región sirven de base para } \\
\text { replicar el proyecto en otras zonas con condiciones socio- } \\
\text { económicas similares. El aprendizaje obtenido tanto por } \\
\text { la comunidad local como por la comunidad educativa y } \\
\text { su participación activa constituye una herramienta clave } \\
\text { para alcanzar el desarrollo sostenible de la región. }\end{array}$ \\
\hline Convenio INPEC & $\begin{array}{l}\text { Se han ejecutado proyectos con las penitenciarias del } \\
\text { Buen Pastor y La Picota, capacitando a la población de } \\
\text { reclusos para el trabajo }\end{array}$ & \\
\hline $\begin{array}{l}\text { Convenio Municipio de } \\
\text { Castilla La Nueva, Meta }\end{array}$ & $\begin{array}{l}\text { Con este municipio se realizo la capacitación de la } \\
\text { comunidad en aspectos de recreación, deporte e } \\
\text { instauración de escuelas recreodeportivas }\end{array}$ & \\
\hline
\end{tabular}

También bajo el Programa de Gestión Tecnológica, se encuentra el de Incubadora de Empresas, el cual busca la creación de negocios exitosos y competitivos, en donde las empresas seleccionadas sean asistidas y monitoreadas individualmente, mediante capacitación, asesoría y consultoría especializada, de acuerdo a la etapa de desarrollo en que se encuentren. En el marco de este subprograma, está articulado un evento que se realiza semestralmente, denominado La muestra Empresarial, en el cual los estudiantes exponen el desarrollo de empresas comerciales, que nacen como prototipos a escalar hacia empresas de tipo comercial, existiendo ejemplos de estudiantes que, gracias a este ejercicio académico, hoy gerencian sus propias empresas.

Vale la pena recalcar que, con el Programa de Gestión Tecnológica, se han adelantado convenios con CETELCA, CORPOICA y COLCIENCIAS, donde se tiene estandarizados modelos de producción de embriones bovinos in Vitro; con CORPOICA, SENA y la Universidad de La Salle, se cuenta con modelos silvopastoriles de alimentación bovina en el trópico alto y, en convenio con el INPEC, se han ejecutado proyectos con la penitenciaria de Acacias, Meta, estableciendo sistemas de producción limpia en porcinos, con el uso y el manejo de excretas en los procesos de alimentación y la administración o conducción ambiental de las piaras.

\section{En el programa de prácticas académicas}

Se conjugan, en este programa, una serie de actividades ligadas a los procesos académicos de las distintas facultades, como acciones individuales de estudiantes de últimos semestres, en pregrado o postgrado, centradas en la aplicación de conocimientos teóricos y en el desarrollo de habilidades en espacios laborales concretos y que buscan contribuir con el mejoramiento del medio social y productivo. Pasantías, Prácticas Empresariales, Rotaciones e Internados son modalidades de las prácticas académicas. La Universidad ha suscrito más de 200 convenios con instituciones públicas y privadas, en las cuales se realiza este tipo de trabajo. Como práctica académica y que a la vez le ha permitido a la U.D.C.A posesionarse, como la única Institución de Educación Superior, en el medio de los equinos, es su anual Exposición Equina Universitaria que, durante 24 años e ininterrumpidamente, ha ejecutado satisfactoriamente. Es un evento que ha congregado a los más destacados criadores de caballos de paso fino colombiano, trocha y galope y otros andares y que mereció el reconocimiento de FEDEQUINAS, como exposición grado A. 


\section{En el programa de educación permanente o continua}

Tiene por objetivo adelantar propuestas de capacitación, como modalidad de Educación No Formal, a través de Cursos, Seminarios, Congresos, Talleres, Diplomados, Simposios de Actualización, entre otros, de carácter nacional e internacional, dirigido a estudiantes, egresados, profesionales y, en fin, a la comunidad en general y conducentes a la solución de problemas sentidos en la sociedad. Es política institucional, semestralmente, programar como mínimo dos o más eventos nacionales y uno al año, a nivel internacional por facultad, destacándose la realización de varias versiones de eventos ya tradicionales en el mundo académico como son: El Seminario Internacional de Agroforestería. El seminario internacional de infectología bovina y El seminario internacional Universidad Ambiente.

\section{En el programa de preservación de la cultura nacional e internacional}

Se busca con este programa incrementar el acervo cultural, nacional e internacional de la comunidad, fortaleciendo la identidad de los valores culturales, en sus diversas manifestaciones artísticas, intelectuales y materiales, manteniendo el equilibrio con los aportes de la cultura internacional. La Universidad materializó estos objetivos mediante la creación del Centro de Arte y Cultural. La Universidad ha sido sede de más de 30 exposiciones de arte, en las cuales se ha tenido oportunidad de disfrutar, en el Hall de las Artes, de obras de los más connotados artistas nacionales e internacionales, entre ellos, Luis Eduardo Garzón "El Tigre”, David Manzur, Ángel Loochkrartt, Gastón Bettelli, Zulema Hani, Germán Tessarolo, Carlos Rodríguez, Augusto Rendón, Beatriz y Lucía Gómez, Jorge Riveros, Manuel Estrada, Umberto Giangrandi, Santiago Cárdenas, Eduardo Esparza, Pilar Copete, Margarita Ariza, entre otros, quienes través de su técnica, muestran su grandeza artística.

\section{En el programa de comunicación y difusión}

Se constituye en el artífice de los procesos e instrumentos que permiten volver efectiva la difusión y la divulgación de aquellas actividades académicas, artísticas, técnicas, tecnológicas y culturales que realiza la Universidad, a través de diferentes medios masivos de comunicación.
Con el Fondo de Publicaciones, se cumple el objetivo de promover y de difundir el material académico, científico y cultural emanado por los miembros de la comunidad universitaria y algunos invitados especialistas externos, y expuestos en libros, manuales y cartillas, entre otros. Son obras relacionadas con la actividad universitaria y su proyección a la sociedad. Merece una mención destacada, la edición y publicación semestral de la revista científica Revista U.D.C.A Actualización E Divulgación Científica, que inició su circulación en el año 1998. Actualmente, se encuentra indexada en Chemical Abstracts, en $C A B$ Abstracts, en el Índice Biliográfico Nacional PUBLINDEX, categoría "B", reseñada en el Índice Latinoamericano de Revistas Científicas y Tecnológicas LATINDEX e incluida en la Base de Datos PERIÓDICA, UNAM, México.

\section{En el programa de exalumnos}

Este programa es una política institucional, mediante la cual se materializa el seguimiento y acompañamiento de los egresados, generando información de primera mano, que permita valorar el impacto social de los programas, retroalimentar los procesos académicos y contar con una masa crítica inserta en los sectores académicos, gremiales, productivos y empresariales. Cuenta con políticas que orientan a la Institución en acciones respecto a sus exalumnos, las cuales se resumen en: ofrecer descuentos para los egresados que decidan adelantar estudios a nivel de postgrado en la U.D.C.A; privilegiar la vinculación de los más destacados, como docentes, bajo el programa de "Docentes en Formación"; orientar a los exalumnos que decidan adelantar estudios de postgrado en el exterior sobre universidades y programas que ofrecen las distintas instituciones y con las cuales la Universidad tiene convenios activos; organizar, conjuntamente con la Asociación de Exalumnos AEXUDCA, encuentros nacionales y regionales periódicos, como mecanismo de integración con la Institución; actualizar la base de datos para conocer su ubicación laboral y desempeño, para lo cual utilizan diversos mecanismos, incluyendo las redes electrónicas de comunicación y la página WEB de la Institución; vincular exalumnos en los procesos de autoevaluación, actualización y renovación curricular, para conocer las necesidades reales del sector productivo respecto al tipo de profesional que debe formar la U.D.C.A; organizar y ofrecer cursos de Educación Permanente que permitan a los exalumnos actualizar sus conocimientos en áreas de su interés y, finalmente, contar con exalumnos de los distintos programas académicos de la U.D.C.A, 
como miembros activos de los Comités Académicos de Facultad, Consejos de Facultad, Consejo Académico y Consejo Directivo de la Institución.

\section{En el programa de convenios y alianzas estratégicas nacionales e internacionales}

La Universidad, con el propósito de participar en el desarrollo de la región en la que ejerce su influencia, ha suscrito convenios nacionales e internacionales, que le han permitido aportar, desde la experiencia y el ámbito académico, a diversas instituciones y organizaciones, con proyectos de investigación, con pasantías de estudiantes y con asesorías docentes. Estas acciones han permitido además desarrollar proyectos especiales con entidades nacionales e internacionales, al tiempo que posicionan la Universidad en el ámbito de la flexibilidad y la movilidad académicas, la internacionalización del conocimiento y hacer honor al carácter de UNIVERSIDAD de la U.D.C.A (Tabla 3).

Tabla 3. Convenios realizados entre la U.D.C.A y diferentes estamentos del Gobierno Nacional y Educación Superior.

\begin{tabular}{|c|c|}
\hline ENTIDAD (ES) & OBJETO DEL CONVENIO \\
\hline $\begin{array}{l}\text { Universidades de Antioquia, Tolima, Caldas, Córdoba, } \\
\text { Amazonia, Surcolombiana, Francisco de Paula Santander- } \\
\text { Ocaña, Pedagógicay Tecnológica de Colombia, Pedagógica } \\
\text { Nacional, Nacional Abierta y a Distancia, Javeriana, } \\
\text { Rosario, Bosque, Colegio Mayor de Cundinamarca, } \\
\text { Escuela Colombiana de Ingeniería. }\end{array}$ & $\begin{array}{l}\text { Mantener una constante dinámica de intercambio académico, de auto-evaluación, de } \\
\text { revisión e innovación curricular, de oferta de programas conjuntos y de capacitación } \\
\text { docente. }\end{array}$ \\
\hline $\begin{array}{l}\text { Ministerios de Agricultura y Desarrollo Rural, de Ambiente, } \\
\text { Vivienda y Desarrollo Territorial. }\end{array}$ & $\begin{array}{l}\text { Desarrollo permanente de proyectos conjuntos, esto le ha permitido a la Universidad } \\
\text { ser invitada a conformar el equipo de evaluadores de proyectos que se ejecutan } \\
\text { desde dichos ministerios; siendo honroso el hecho que la U.D.C.Aocupa la Secretaría } \\
\text { Técnica de la Red Colombiana de Formación Ambiental. }\end{array}$ \\
\hline $\begin{array}{l}\text { Gobernación de Cundinamarca y las Secretarías de } \\
\text { Agricultura de Cundinamarca, Boyacá, Casanare, Meta, } \\
\text { Arauca, Caquetá, Huila y Santander. }\end{array}$ & $\begin{array}{l}\text { Se han ejecutado proyectos de Capacitación, dirigida tanto a Profesionales vinculados } \\
\text { a las instituciones como de poblaciones de las áreas de influencia. }\end{array}$ \\
\hline $\begin{array}{l}\text { COLCIENCIAS, ICA y CORPOICA, instituciones líderes } \\
\text { en Investigación. }\end{array}$ & $\begin{array}{l}\text { Se ha logrado integrar equipos de trabajo tanto para la realización de trabajos } \\
\text { conjuntos como para actuar de pares académicos - evaluadores de proyectos }\end{array}$ \\
\hline CORPOICA & $\begin{array}{l}\text { Se estableció una alianza estratégica, mediante la cual se dio vida a LAESCUELADE } \\
\text { PENSAMIENTO Y FORMACIÓN DE RECURSOS HUMANOS EN AGRICULTURA } \\
\text { TROPICAL, siendo los resultados el poder ofrecer, dos programas de especialización: } \\
\text { uno, en Nutrición Animal Aplicada y, el otro, en Producción Animal. Queda, en el } \\
\text { corto plazo, la oferta de una tercera especialización en Manejo Sostenible del } \\
\text { Sistema Suelo - Agua - Planta en el Trópico y programas de Maestría en Ciencias } \\
\text { Veterinarias, Ciencias Agrícolas y Agroforestería, respectivamente. }\end{array}$ \\
\hline Departamento Nacional de Planeación e ICONTEC & $\begin{array}{l}\text { Se pretende estar a tono con las proyecciones de la vida nacional y contar con } \\
\text { las herramientas que permitan velar por la calidad de los procesos, que deben ser } \\
\text { incorporados, como prioridades, en el quehacer cotidiano de la Universidad. }\end{array}$ \\
\hline $\begin{array}{l}\text { CAR, el Instituto Geográfico Agustín Codazzi, DANE y la } \\
\text { Asociación de Ingenieros Geógrafos. }\end{array}$ & $\begin{array}{l}\text { Se han diseñado proyectos que tienen que ver con el ordenamiento territorial y el } \\
\text { manejo racional de recursos naturales. }\end{array}$ \\
\hline $\begin{array}{l}\text { FEDEGÁN, ASOCEBÚ, ASOPORCINOS, } \\
\text { ASOHOLSTEIN, ASOCRIOLLO, FEDEQUINAS, } \\
\text { ASDEPASO, CENIACUA, FEDEPALMA, FEDEPAPA, } \\
\text { FENALCE, Federación Nacional y Comités Regionales } \\
\text { de Cafeteros }\end{array}$ & Se han ejecutado proyectos de investigación y validación tecnológica. \\
\hline
\end{tabular}


Membresías Nacionales: La Universidad, es miembro activo de instituciones nacionales como: ICONTEC, FORO DE PRESIDENTES, CÁMARA DE COMERCIO DE BOGOTÁ, ASCUN, OUN, UNIVERSIA, ASCOFAME, ACOFAE, ACOFI, ASFAMEVEZ, CENIACUA, CORPOICA, ACOVEZ, RCI, RED TEMÁTICA DE EDUCACIÓN AMBIENTAL, RED DE DESARROLLO SOSTENIBLE Y MEDIO AMBIENTE, REDESMA y DAMA-PREAR.

Membresías Internacionales: La Universidad, tiene una participación activa en asociaciones internacionales permitiendo la integración con otras culturas representando un gran aporte para la internacionalización de su comunidad universitaria. Ellas son: AUALCPI (Asociación de Universidades de América Latina y el Caribe para la Integración): Miembro activo y vicepresidente de la asociación; CUIDES (Consejo Universitaria Interamericano para el Desarrollo Económico y Social): Miembro del Consejo Directivo. Ocupa la Secretaría General; IAUP (International Association of University President): Miembro del Consejo Directivo y ocupa la Presidencia para el Capítulo Colombia; GULERPE (Grupo Universitario latinoamericano de estudios para la Reforma y el Perfeccionamiento de la Educación); UDUAL (Unión de Universidades de América Latina);RED UREL (Red de Universidades Regionales Latinoamericanas) Miembro del Consejo Directivo-Vicepresidente; Red Colombiana de Cooperación Internacional RCI. , y Redisaf: Red Andina de Investigaciones en Sistemas Forestales.

Adicionalmente hace parte activa de programas internacionales como:

- Programa de Cooperación Interuniversitaria ALE. Programa International Association for the Exchange of Students for Technical Experience - IAESTE.

- Programa de Intercambio Académico Técnico y Científico RCI y - El Programa PAME- UDUAL.

\section{Ejecuciones en el campo ambiental}

PROYECTO AMBIENTAL INSTITUCIONAL: La Universidad, en honor a su Misión, incorpora el saber ambiental y los criterios de sostenibilidad en todos sus quehaceres, resaltando la creación y puesta en marcha de su propio proyecto ambiental, resumido así:

PROYECTO AMBIENTAL INSTITUCIONAL - PAI, se cimienta en dos grandes planes: PIMA y PISA, los cuales buscan dar cumplimiento a los compromisos adquiridos en la Política Ambiental Institucional. Respecto al PIMA, esta orientado a la optimización del desempeño ambiental en el contexto del manejo responsable de los recursos naturales, energéticos e institucionales e incorpora el tema de atención y prevención de desastres. Los programas que conforman el PIMA son: Programa de Manejo Integral de Residuos, Programa de Manejo Forestal y Paisajístico, Programa de Manejo del Recurso Hídrico, Programa de Manejo Eficiente de Recursos y Programa de Atención y prevención de Desastres. Por su parte el PISA, pretende dar cumplimiento al compromiso que asumen todas las unidades académicas en el liderazgo en la formación del ciudadano, muy bien calificado en lo científico, ambientalmente responsable y consciente de su papel de constructores de una nueva sociedad en armonía con el entorno. Los programas que conforman el PISA son: Programa de Incorporación de la Dimensión Ambiental en el Currículo, Programa de Incorporación del Saber Ambiental en las Asignaturas, Programa de Fomento a la Investigación en temas Ambientales, Programa de Proyección de Estrategias de Mejoramiento Ambiental, a la Comunidad.

Recibido: Febrero 26 de 2008

Aceptado: Mayo 14 de 2008 